\title{
PENGARUH KEEFEKTIFAN PENGENDALIAN INTERNAL TERHADAP \\ KECENDERUNGAN KECURANGAN AKUNTANSI PADA BADAN PENGELOLA KEUANGAN ASET DAN PENDAPATAN DAERAH (BPKAPD) KOTA BAUBAU
}

\author{
La Ode Muhammad Hasrul Adan \\ Program Studi Akuntansi, Fakultas Ekonomi, \\ Universitas Muhammadiyah Buton, Baubau, Indonesia \\ Email : laodehasrul.umb@gmail.com
}

\begin{abstract}
ABSTRAK
Dalam melaksanakan kegiatannya, lembaga pemerintahan pada umumnya sangat memerlukan sistem akuntansi yang efisien dan efektif. Sistem informasi akuntansi yang baik dapat diciptakan melalui pengendalian internal (internal control) yang memadai.

Tujuan dari penelitian ini untuk mengetahui bagaimana pengaruh keefektifan pengendalian internal terhadap kecenderungan kecurangan akuntansi pada Badan Pengelola Keuangan, Aset dan Pendapatan Daerah (BKAPD) Kota Baubau. Jenis penelitian ini adalah penelitian kuantitatif, populasi yang akan digunakan adalah seluruh pegawai di lingkungan BPKAPD Kota Baubau yang berjumlah 45 orang. Dari hasil penelitian yang didapatkan keefektifan pengendalian internal berpengaruh signifikan terhadap kecenderungan kecurangan akuntansi.
\end{abstract}

\section{Kata Kunci : Keefektifan Pengendalian Internal dan Kecenderungan Kecurangan Akuntansi}

\section{ABSTRACT}

In carrying out its activities, government institutions generally require an efficient and effective accounting system. A good accounting information system can be created through adequate internal control.

The purpose of this study is to find out how the effect of the effectiveness of internal control on accounting fraud tendencies in the Baubau City Financial, Asset and Income Management Agency (BKAPD). The type of this research is quantitative research, the population that will be used is all employees in the BPKAPD Baubau City, amounting to 45 people. From the results of the study, the effectiveness of internal control has a significant effect on accounting fraud tendencies.

Keywords: Effectiveness of Internal Control and Accounting Fraud Trends 


\section{PENDAHULUAN}

Dalam melaksanakan kegiatannya, lembaga pemerintahan pada umumnya sangat memerlukan sistem akuntansi yang efisien dan efektif. Sistem informasi akuntansi yang baik dapat diciptakan melalui pengendalian internal (internal control) yang memadai [1].

Pengendalian internal yang baik memungkinkan manajemen siap menghadapi perubahan dan persaingan global secara tepat untuk kemajuan yang akan datang. Jika pengendalian internal suatu perusahaan lemah maka kemungkinan terjadinya kesalahan dan kecurangan semakin besar. Sebaliknya, jika pengendalian internalnya kuat, maka kemungkinan terjadinya kecurangan dapat diperkecil.

Keefektifan pengendalian internal mempunyai pengaruh yang besar dalam upaya pencegahan kecenderungan kecurangan akuntansi. Adanya pengendalian internal yang efektif memungkinkan terjadinya pengecekan silang (cross check) terhadap pekerjaan seseorang oleh orang lain. Hal ini menurunkan peluang terjadinya kecenderungan kecurangan dan mengalokasikan kesalahan [2].

Di Indonesia, kecurangan dalam bidang akuntansi yang paling sering terjadi ialah kejahatan kerah putih (white-collar crime) atau yang lebih dikenal dengan sebutan korupsi. Kejahatan ini dilakukan oleh seseorang yang memiliki kedudukan dan jabatan penting di lingkungan organisasinya. Kejahatan tersebut dilakukan dengan memanfaatkan wewenang yang dimilikinya untuk melakukan kecurangan tanpa dicurigai oleh siapapun.

Kecurangan (fraud) terjadi baik pada sektor pemerintahan maupun pada sektor swasta tanpa terkecuali, Di sektor pemerintah misalnya adanya praktik mark-up dalam proyek - proyek yang dikerjakan oleh pemerintah yang dilakukan oleh para pejabat dan yang paling sering ialah bisnis plat merah atau bisnis pejabat (penguasa) dan keluarga serta kroni mereka yang menjadi pemasok atau rekanan di lembaga - lembaga pemerintah dan di dunia bisnis sekalipun [3]. 
Untuk membantu menyelesaikan masalah kecurangan dalam akuntansi, dikembangkan suatu sub ilmu akuntansi dalam auditing yaitu bidang audit kecurangan (fraud audit). Audit kecurangan terdiri atas dua komponen utama yaitu audit kecurangan yang proaktif (proactive fraud audit) dan audit investigatif (investigative audit). Untuk proactive fraud audit dilakukan kajian sistem yang bertujuan mengidentifikasikan potensi - potensi atau resiko terjadinya fraud, Sedangkan investigative audit, bertujuan untuk membuktikan terjadinya kecurangan (fraud) [4].

Fraud adalah kejahatan yang dapat ditangani dengan dua cara, yaitu dengan mencegah dan mendeteksi fraud. Pencegahan terhadap kecurangan (fraud) dimulai dengan pengendalian intern, disamping itu dilakukan pencegahan dengan dua konsep penting lainnya untuk mencegah kecurangan (fraud) yakni menanamkan kesadaran tentang adanya kecurangan (fraud awareness) dan upaya menilai risiko terjadinya kecurangan (fraud risk assessment) [5].

Melalui pengendalian intern, fraud awareness, dan fraud risk assessment setiap perusahaan yang menerapkannya berharap untuk dapat mencegah, menghilangkan bahkan menekan sedapat mungkin need dan greed yang mengawali terjadinya kecurangan (fraud) yang dilakukan sejak menerima seseorang sebagai karyawan dan membantu untuk mengurangi unsur peluang kecurangan, yang dapat timbul di perusahaan dan membuat peluang bagi karyawan untuk melakukan kecurangan (fraud).

Berdasarkan latar belakang masalah diatas maka rumusan masalah pada penelitian ini adalah bagaimana pengaruh keefektifan pengendalian internal terhadap kecenderungan kecurangan akuntansi pada Badan Pengelola Keuangan, Aset dan Pendapatan Daerah (BKAPD) kota Baubau?

Penelitian ini dibatasi pada pengujian pengaruh keefektifan pengendalian internal terhadap kecenderungan kecurangan akuntansi tahun anggaran 2017. 


\section{METODE PENELITIAN}

\section{Populasi, dan Sampel}

Populasi adalah wilayah generalisasi yang terdiri atas objek atau subjek yang memiliki kualitas dan karakteristik tertentu yang ditetapkan oleh peneliti untuk dipelajari dan kemudian ditarik kesimpulan [6]. Populasi dalam penelitian ini adalah seluruh pegawai di Badan Pengelola Keuangan, Aset dan Pendapatan Daerah (BPKAPD) Kota Baubau. Sedangkan data yang dijadikan sampel adalah seluruh pegawai di lingkungan BPKAPD Kota Baubau yang berjumlah 45 orang.

\section{Sumber Data}

Sumber data yang digunakan dalam penelitian ini adalah data primer dan data sekunder. Data primer adalah data hasil wawancara langsung dengan pihak yang terkait dengan pengendalian internal dan bagian bagian akuntansi. Sedangkan data sekunder adalah data yang diperoleh dari dokumen-dokumen baik kualitatif maupun kuantitatif yang terkait dengan pengendalian internal [7].

\section{Skala Pengukuran Variabel}

Skala pengukuran untuk variabel $\mathrm{X}$ dan variabel $\mathrm{Y}$ adalah ordinal dengan tipe skala likert. Dengan pengukuran menggunakan skala likert ini, responden diminta mengisi pernyataan dalam skala ordinal berbentuk verbal dalam jumlah kategori tertentu. Untuk setiap pilihan jawaban diberi skor $1=$ sangat tidak setuju, 2 = tidak setuju, $3=$ kurang setuju, $4=$ setuju, dan $5=$ sangat setuju.

\section{Uji Kualitas Data}

Kualitas data yang dihasilkan dari penggunan instrumen penelitian dapat dievaluasi melalui uji reliabilitas dan validitas [8]. Pengujian yang dimaksud adalah untuk mengetahui konsistensi dan akurasi data yang dikumpulkan dari penggunaan instrumen. Prosedur pengujian kualitas data adalah sebagai berikut : 
a) Uji Validitas

Uji validitas dilakukan dengan menilai correlated item. Total correlation dengan kriteria sebagai berikut : Jika nilai rhitung lebih besar dari rtabel dan nilainya positif, maka butir pertanyaan atau indikator tersebut dikatakan "valid”. Namun sebaliknya, jika nilai rhitung lebih kecil rtabel, maka pertanyaan tersebut dapat dikatakan "tidak valid" [9].

b) Uji Reliabilitas.

Pengujian ini dilakukan dengan menghitung koefisien Cronbach alpha dari masing-masing instrumen dalam suatu variabel. Instrumen dapat dikatakan handal (reliabel) bila memiliki koefisien cronbach alpha lebih dari 0,60 .

\section{Uji Hipotesis}

Pengujian hipotesis dilakukan dengan menggunakan model regresi linier sederhana dengan persamaan sebagai berikut :

$$
\hat{y}=a+\beta x
$$

Dimana :

$\hat{Y} \quad=$ Variabel terikat (Kecenderungan kecurangan)

$\mathrm{x}=$ Variabel bebas (Pengendalian internal)

$\mathrm{a} \quad=$ Konstanta

$\beta=$ Koefisien Regresi

\section{a) Uji Parsial (Uji t)}

Uji t statistik dimaksudkan untuk menguji pengaruh secara parsial antara variabel bebas terhadap variabel terikat dengan asumsi bahwa variabel lain dianggap konstan, dengan tingkat kenyakinan 95\% $(\alpha=0,05)$.

b) Koefisien Determinasi $\left(\mathrm{R}^{2}\right)$

Koefisien determinasi (adjusted R2) yaitu angka yang menunjukkan besarnya kemampuan varians atau penyebaran dari variabel-variabel bebas 
yang menerangkan variabel terikat atau angka yang menunjukkan seberapa besar variabel terikat dipengaruhi oleh variabel bebasnya [10].

\section{HASIL DAN PEMBAHASAN}

\section{Hasil Penelitian}

\section{Uji Kualitas Data}

\section{Uji Validitas}

\section{Tabel}

Uji Validitas Variabel (X)

\begin{tabular}{|c|c|c|c|}
\hline Pertanyaan & Nilai Korelasi & $\mathbf{R}_{\text {tabel }}(\mathbf{n}=\mathbf{4 3})$ & Keterangan \\
\hline Pertanyaan 1 & 0,580 & 0,301 & Valid \\
\hline Pertanyaan 2 & 0,914 & 0,301 & Valid \\
\hline Pertanyaan 3 & 0,743 & 0,301 & Valid \\
\hline Pertanyaan 4 & 0,576 & 0,301 & Valid \\
\hline Pertanyaan 5 & 0,929 & 0,301 & Valid \\
\hline Pertanyaan 6 & 0,880 & 0,301 & Valid \\
\hline Pertanyaan 7 & 0,783 & 0,301 & Valid \\
\hline Pertanyaan 8 & 0,615 & 0,301 & Valid \\
\hline Pertanyaan 9 & 0,919 & 0,301 & Valid \\
\hline Pertanyaan 10 & 0,834 & 0,301 & Valid \\
\hline
\end{tabular}

Sumber : Data Diolah SPSS

Dari 10 pertanyaan mengenai keefektifan pengendalian internal berupa ketanggapan yang diajukan penulis kepada responden, 10 pertanyaan dinyatakan valid 
Tabel

Uji Validitas Variabel (Y)

\begin{tabular}{|c|c|c|c|}
\hline Pertanyaan & Nilai Korelasi & $\mathbf{R}_{\text {tabel }}(\mathbf{n}=\mathbf{4 3})$ & Keterangan \\
\hline Pertanyaan 1 & 0,323 & 0,301 & Valid \\
\hline Pertanyaan 2 & 0,331 & 0,301 & Valid \\
\hline Pertanyaan 3 & 0,929 & 0,301 & Valid \\
\hline Pertanyaan 4 & 0,855 & 0,301 & Valid \\
\hline Pertanyaan 5 & 0,748 & 0,301 & Valid \\
\hline Pertanyaan 6 & 0,648 & 0,301 & Valid \\
\hline Pertanyaan 7 & 0,821 & 0,301 & Valid \\
\hline Pertanyaan 8 & 0,659 & 0,301 & Valid \\
\hline Pertanyaan 9 & 0,537 & 0,301 & Valid \\
\hline Pertanyaan 10 & 0,897 & 0,301 & Valid \\
\hline
\end{tabular}

Sumber : Data Diolah SPSS

Dari 10 pertanyaan mengenai kecenderungan kecurangan akuntansi berupa ketanggapan yang diajukan penulis kepada responden, 10 pertanyaan dinyatakan valid.

\section{Uji Reliabilitas}

Tabel 4.6

Uji Reliabilitas

\begin{tabular}{|l|c|c|}
\hline \multicolumn{1}{|c|}{ Variabel } & $\begin{array}{c}\text { Cronbach 's } \\
\text { Alpha }\end{array}$ & $\begin{array}{l}\text { N of } \\
\text { Items }\end{array}$ \\
\hline Keefektifan Pengendalian Interal & 0,942 & 45 \\
\hline $\begin{array}{l}\text { Kecenderungan Kecurangan } \\
\text { Akuntansi }\end{array}$ & 0,897 & 45 \\
\hline
\end{tabular}

$u$

Sumber : Data Diolah SPSS

Dari hasil pengujian reliability dengan menggungakan SPSS dapat dilihat bahwa dari nilai cronbach alpha setiap variabel $>0,5$ maka reliability data tersebut cukup baik.

\section{Uji Asumsi Klasik}

\section{Uji Normalitas}

Pengujian normalitas data dalam penelitian ini menggunakan uji statistik nonparametrik Kolmogorov-Smirnov (K-S), grafik Histogram, dan grafik 
Normal Plot. Uji statistik non parametrik Kolmogorov-Smirnov (K-S) dengan membuat hipotesis:

H0 : Data residual berdistribusi normal.

Ha : Data residual tidak berdistribusi normal

Dalam uji Kolmogorov-Smirnov, pedoman yang digunakan dalam pengambilan keputusan yaitu :

1. Jika nilai signifikasi $<0,05$ maka distribusi data tidak normal.

2. Jika nilai signifikasi $>0,05$ maka distribusi data normal.

Hasil uji Kolmogorov-Smirnov dapat dilihat pada tabel dibawah ini

Tabel

Uji Normalitas

One-sample Kolmogorov-Smirnov Test

\begin{tabular}{|ll|r|}
\hline & & Unstandardized Residual \\
\hline $\mathrm{N}$ & Mean & 45 \\
& & .0000000 \\
Normal Parameters & $\mathrm{a}, \mathrm{b}$ & Std. \\
& Deviation & 1.66926104 \\
& Absolute & .099 \\
Most Extreme & Positive & .082 \\
Differences & Negative & -.099 \\
\multicolumn{2}{l|}{ Kolmogorov-Smirnov Z } & .662 \\
Asymp. Sig. (2-tailed) & .773 \\
\hline
\end{tabular}

a. Test distribution is Normal.

b. Calculated from data.

Pengolahan data tersebut, besarnya nilai Kolmogorov-Smirnov diketahui nilai probabilitas $\mathrm{p}$, yakni 0,773 lebih besar dibandingkan tingkat signifikasi, yakni 0,05 . Hal ini berarti asumsi normalitas terpenuhi.

\section{Gambar}

\section{Histogram}

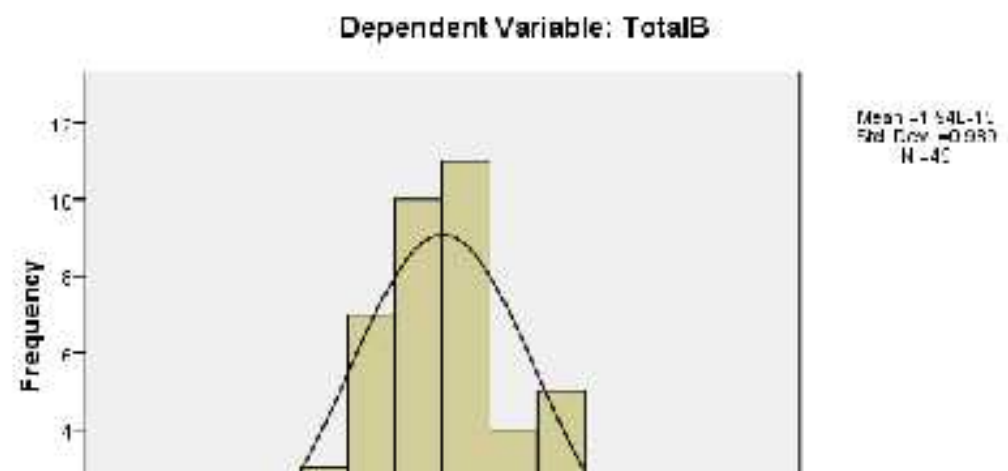


Berdasarkan grafik diatas dapat disimpulkan bahwa distribusi data normal karena grafik histogram menunjukan distribusi data mengikuti garis diagonal yang tidak menceng (skewness) ke kiri maupun ke kanan.

\section{Gambar \\ Grafik P-Plot}

Dependent Variable: TotalB

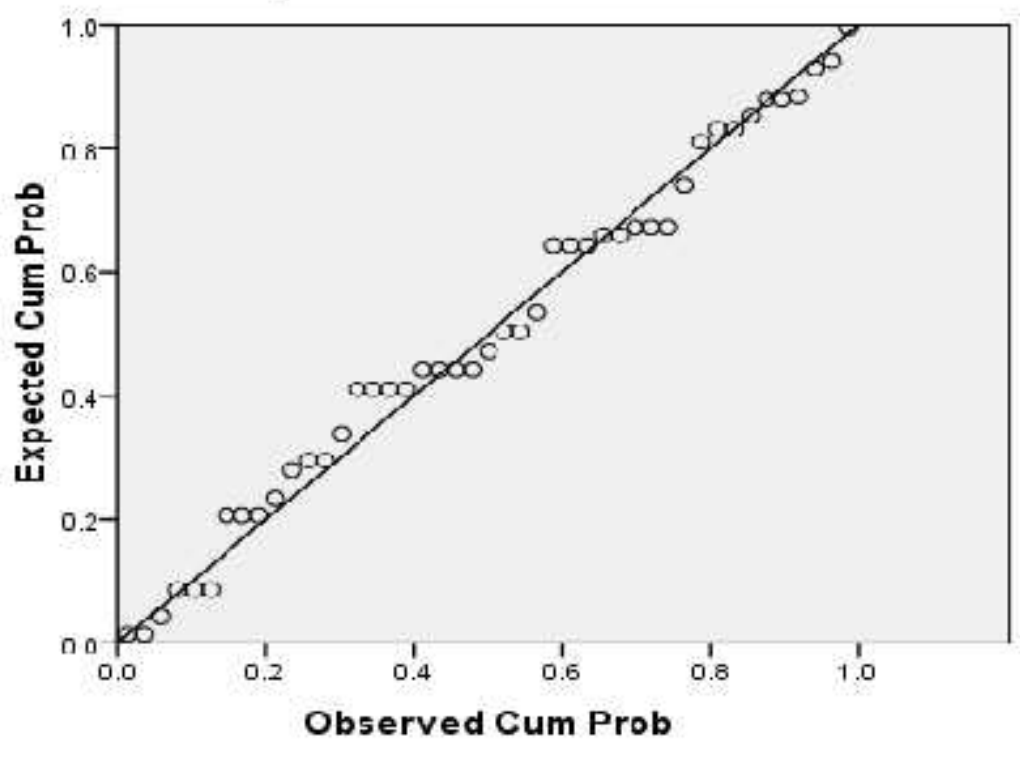

Hasil uji normalitas dengan menggunakan grafik p-plot dibawah ini. Pada grafik normal p-plot, terlihat titik-titik menyebar disekitar garis diagonal serta penyebarannya agak mendekati dengan garis diago9nal sehingga dapat disimpulkan bahwa data dalam model regresi terdistribusi secara normal.

\section{Uji Multikolinearitas}

Uji multikolinearitas bertujuan untuk menguji apakah pada model regresi ditemukan korelasi antara variabel independent. Jika terjadi korelasi maka terdapat masalah multikolinearitas sehingga model regresi tidak digunakan. Mendeteksi ada tidaknya gejala multikolinearitas adalah dengan melihat nilai tolerance dan variance inflation factor (VIF), serta menganalisis matrik korelasi variabel-variabel independen. Besarnya tingkat multikolinearitas yang masih dapat ditolerir, yaitu Tolerance $>0,10$ dan nilai $\mathrm{VIF}<5$. Berikut disajikan tabel hasil pengujian multikolinearitas. 
Tabel

Uji Multikolinearitas

Coefficients $^{\mathrm{a}}$

\begin{tabular}{|c|c|c|c|c|c|c|c|}
\hline \multirow[b]{2}{*}{ Model } & \multicolumn{2}{|c|}{$\begin{array}{l}\text { Unstandardize } \\
\text { d Coefficients }\end{array}$} & \multirow{2}{*}{ 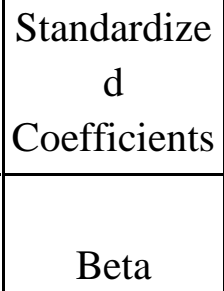 } & \multirow[b]{2}{*}{$\mathrm{t}$} & \multirow[b]{2}{*}{ Sig. } & \multicolumn{2}{|c|}{$\begin{array}{c}\text { Collinearity } \\
\text { Statistics }\end{array}$} \\
\hline & B & $\begin{array}{l}\text { Std. } \\
\text { Error }\end{array}$ & & & & Tolerance & VIF \\
\hline 1 (Constant) & 5.662 & 1.556 & & 3.640 & .001 & & \\
\hline TotalA & .868 & .042 & .954 & 20.820 & .000 & 1.000 & 1.000 \\
\hline
\end{tabular}

a. Dependent Variable: TotalB

Berdasarkan tabel 4.8 diatas, dapat disimpulkan bahwa tidak terjadi gejala multikolinearitas antara variabel independen yang diindikasi dari nilai tolerance keefektifan pengendalian internal lebih besar dari 0,1 . Nilai tolerance keefektifan pengendalian internal adalah 1,00 sedangkan variabel independen keefektifan pengendalian internal juga lebih kecil dari 5 yaitu 1,00 .

\section{Uji Heteroskedastisitas}

Uji heteroskedastisitas bertujuan menguji apakah dalam model regresi terjadi ketidaksamaan variance dari residual satu pengamatan ke pengamatan yang lain, karena untuk melihat apakah terdapat ketidaksamaan varians dari residual satu ke pengamatan ke pengamatan yang lain. Dalam penelitian ini akan digunakan metode chart (Diagram Scatterplot), dengan dasar pemikiran bahwa:

a) Jika ada pola tertentu seperti titik-titik (poin-poin), yang ada membentuk suatu pola tertentu yang beraturan (bergelombang, melebar, kemudian menyempit), maka terjadi heteroskedastisitas.

b) Jika ada pola yang jelas, serta titik-titik menyebar keatas dan dibawah 0 pada sumbu Y maka tidak terjadi heteroskedastisitas 


\section{Gambar}

\section{Scaterplot}

Dependent Variable: TotalB

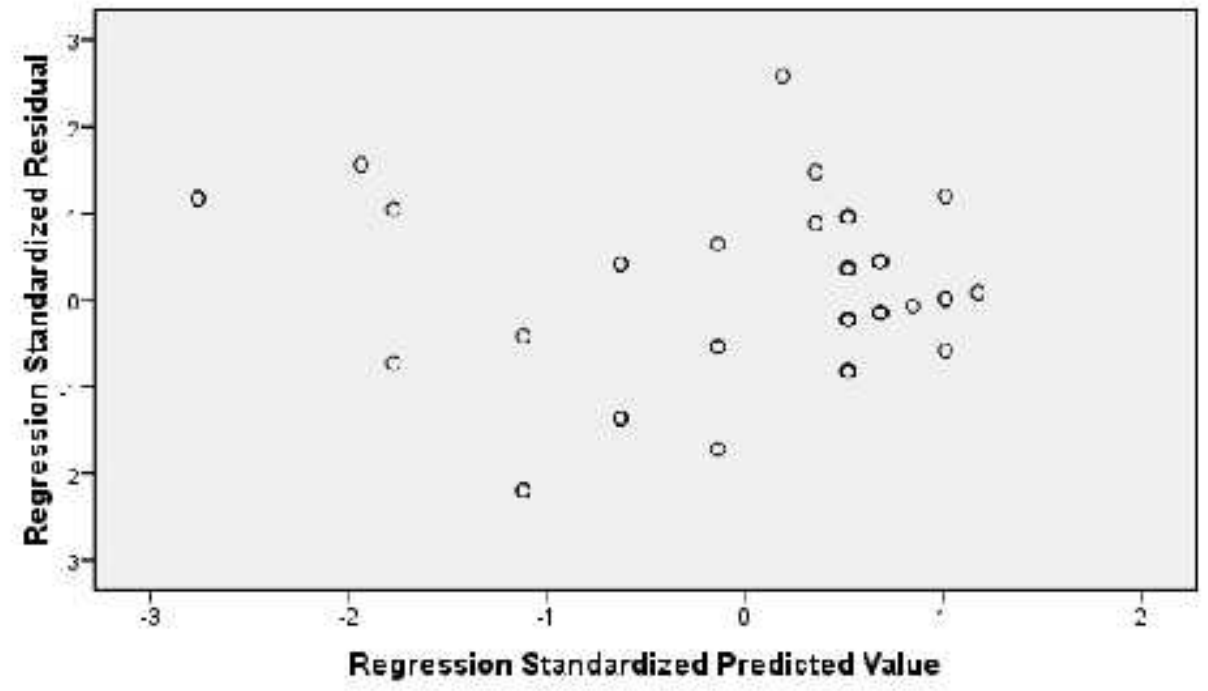

\section{Analisis Regresi}

Dalam pengolahan data dengan menggunakan regresi linier, dilakukan beberapa tahapan untuk mencari hubungan antara variabel independen dan variabel dependen, melalui pengaruh keefektifan pengendalian internal, terhadap kecenderungan kecurangan akuntansi. Berdasarkan hasil pengolahan data dengan program SPSS Versi 21, maka diperoleh hasil sebagai berikut:

\section{Tabel}

\section{Regresi Linear Sederhana}

\begin{tabular}{|c|c|c|c|c|c|c|c|}
\hline \multirow[b]{2}{*}{ Model } & \multicolumn{2}{|c|}{$\begin{array}{l}\text { Unstandardize } \\
\text { d Coefficients }\end{array}$} & \multirow{2}{*}{\begin{tabular}{|c|}
$\begin{array}{c}\text { Standardize } \\
\mathrm{d} \\
\text { Coefficients }\end{array}$ \\
Beta
\end{tabular}} & \multirow[b]{2}{*}{$\mathrm{T}$} & \multirow[b]{2}{*}{ Sig. } & \multicolumn{2}{|c|}{$\begin{array}{c}\text { Collinearity } \\
\text { Statistics }\end{array}$} \\
\hline & B & $\begin{array}{l}\text { Std. } \\
\text { Error }\end{array}$ & & & & Tolerance & VIF \\
\hline 1 (Constant) & 5.662 & 1.556 & & 3.640 & .001 & & \\
\hline TotalA & .868 & .042 & .954 & 20.820 & .000 & 1.000 & 1.000 \\
\hline
\end{tabular}

a. Dependent Variable: TotalB 
Berdasarkan tabel diatas didapatlah persamaan regresi linear sebagai berikut :

$$
\mathrm{KK}=\mathbf{5 , 6 6 2}+\mathbf{0 , 8 6 8 x}
$$

Keterangan:

1. Konstanta sebesar 5,662 menunjukkan bahwa apabila tidak ada variabel independen $(X=0)$ maka nilai kecenderungan kecurangan sebesar 5,662.

2. $\beta$ sebesar 0,868 menunjukkan bahwa setiap kenaikan keefektifan pengendalian internal sebesar $1 \%$ akan diikuti oleh peningkatan kecenderungan kecurangan akuntansi sebesar 0,868 dengan asumsi variabel lain tetap.

\section{Analisis Koefisien Regresi}

Nilai koefisien korelasi (R) menunjukkan seberapa besar korelasi atau hubungan antara variabel independen dengan variabel dependen.

Tabel 4.10

\section{Koefisien Determinasi}

\begin{tabular}{|l|r|r|r|r|r|}
\hline Model & \multicolumn{1}{|c|}{$\mathrm{R}$} & R Square & $\begin{array}{c}\text { Adjusted R } \\
\text { Square }\end{array}$ & $\begin{array}{c}\text { Std. Error of } \\
\text { the Estimate }\end{array}$ & $\begin{array}{c}\text { Durbin- } \\
\text { Watson }\end{array}$ \\
\hline 1 & $.954^{\mathrm{a}}$ & .910 & .908 & 1.689 & 1.587 \\
\hline
\end{tabular}

a. Predictors: (Constant), TotalA (Keefektifan pengendalian internal).

b. Dependent Variable: TotalB (Kecenderungan kecurangan).

Hasil pengujian dengan menggunakan koefisien determinasi menunjukkan bahwa nilai $\mathrm{R}=0,954$ berarti hubungan antara keefektifan pengendalian internal terhadap kecenderungan kecurangan akuntansi sebesar 95.4\%. Artinya hubungannya erat. Semakin besar R berarti hubungan semakin erat.

$R$ Square sebesar 0,910 berarti $91.1 \%$ kecenderungan kecurangan akuntansi dipengaruhi oleh kesadaran keefektifan pengendalian internal. Sisanya $8.9 \%$ dijelaskan oleh variabel-variabel lainnya yang tidak masuk dalam model penelitian ini. 
Adjusted $R$ Square sebesar 0,908 berarti $90.8 \%$ keefektifan pengendalian internal terhadap kecenderungan kecurangan sementara sisanya 9.2\% dijelaskan oleh variabel lainnya yang tidak masuk dalam model penelitian ini.

\section{Uji Hipotesis}

\section{Uji t}

Uji t digunakan untuk menguji signifikansi konstanta dan setiap variabel independennya. Berdasarkan hasil pengolahan SPSS versi 21, diperoleh hasil sebagai berikut :

\section{Tabel}

\section{Uji t}

\begin{tabular}{|l|r|r|r|r|r|r|r|}
\hline & \multicolumn{1}{|c|}{$\begin{array}{c}\text { Unstandardize } \\
\mathrm{d} \text { Coefficients }\end{array}$} & $\begin{array}{c}\text { Standardize } \\
\mathrm{d} \\
\text { Coefficients }\end{array}$ & & & \multicolumn{2}{|c|}{$\begin{array}{c}\text { Collinearity } \\
\text { Statistics }\end{array}$} \\
\cline { 2 - 9 } Model & $\mathrm{B}$ & $\begin{array}{r}\text { Std. } \\
\text { Error }\end{array}$ & \multicolumn{1}{c|}{ Beta } & $\mathrm{t}$ & Sig. & Tolerance & VIF \\
\hline 1 (Constant) & 5.662 & 1.556 & & 3.640 & .001 & & \\
TotalA & .868 & .042 & .954 & 20.820 & .000 & 1.000 & 1.000 \\
\hline
\end{tabular}

a. Dependent Variable: TotalB

Dari tabel regresi dapat dilihat besarnya $t_{\text {hitung }}$ untuk variabel keefektifanpengendalian internal sebesar 20.820 dengan nilai signifikan0,000, sedangkan $t_{\text {tabel }}$ adalah 1,68 sehingga $t_{\text {hitung }}>t_{\text {tabel }}(20,820>1,68)$, makakeefektifan pengendalian internal menunjukkan angka $<0,05(0,000<0,05)$, maka H0 ditolak dan Ha diterima, artinya keefektifan pengendalian internal berpengaruh signifikan terhadap kecenderungan kecurangan akuntansi.

\section{Uji F}

Untuk melihat pengaruh keefektifan pengendalian internal terhadap kecenderungan kecurangan akuntansi secara simultan dapat dihitung dengan 
menggunakan F test. Berdasarkan hasil pengolahan data dengan program SPSS 21, maka diperoleh hasil sebagai berikut :

\section{Tabel}

\section{Uji F}

ANOVA ${ }^{b}$

\begin{tabular}{|c|c|c|c|c|c|c|}
\hline \multicolumn{2}{|c|}{ Model } & $\begin{array}{l}\text { Sum of } \\
\text { Squares }\end{array}$ & df & Mean Square & $\mathrm{F}$ & Sig. \\
\hline \multirow[t]{3}{*}{1} & Regression & 1235.975 & 1 & 1235.975 & 433.488 & $.000^{\mathrm{a}}$ \\
\hline & Residual & 122.603 & 43 & 2.851 & & \\
\hline & Total & 1358.578 & 44 & & & \\
\hline
\end{tabular}

a. Predictors: (Constant), TotalA

b. Dependent Variable: TotalB

Dari uji ANOVA atau $F$ test, diperoleh $F_{\text {hitung }}$ sebesar 433.488 dengan tingkat signifikansi 0,000 , sedangkan $\mathrm{F}_{\text {tabel }}$ Sebesar 3,09 dengan signifikansi 0,05. Berdasarkan hasil tersebut dapat disimpulkan bahwa keefektifan pengendalian internal secara simultan berpengaruh signifikan positif terhadap kecenderungan kecurangan karena $F_{\text {hitung }}>F_{\text {tabel }}(433.488>3,09)$ dan signifikansi penelitian < $0,05(0,000<0,05)$.

\section{Pembahasan}

\section{Pengaruh Keefektifan Pengendalian Internal Terhadap Kecenderungan Kecurangan Akuntansi}

Dari tabel regresi dapat dilihat besarnya $t_{\text {hitung }}$ untuk variabel keefektifan pengendalian internal sebesar 20,820 dengan nilai signifikan 0,000 , sedangkan $t_{\text {tabel }}$ adalah 1,68 sehingga $t_{\text {hitung }}>t_{\text {tabel }}(20,820>1,68)$, maka keefektifan pengendalian internal menunjukkan angka $<0,05(0,000<0,05)$, maka $\mathrm{H} 0$ ditolak dan Ha diterima, artinya keefektifan pengendalian internal berpengaruh signifikan terhadap kecenderungan kecurangan akuntansi.

Dari uji ANOVA atau $F$ test, diperoleh $F_{\text {hitung }}$ sebesar 433.488 dengan tingkat signifikansi 0,000, sedangkan $\mathrm{F}_{\text {tabel }}$ sebesar 3,09 dengan signifikansi 0,05. 
Berdasarkan hasil tersebut dapat disimpulkan bahwa keefektifan pengendalian internal secara simultan berpengaruh signifikan positif terhadap kecenderungan kecurangan karena $F_{\text {hitung }}>F_{\text {tabel }}(433.488>3,09)$ dan signifikansi penelitian < $0,05(0,000<0,05)$.

\section{KESIMPULAN}

Berdasarkan hasil analisis data dan pembahasan yang telah dikemukakan dalam Bab IV, maka kesimpulan yang dapat diambil dari penelitian ini adalah berdasarkan tabel regresi dapat dilihat bahwa besarnya $t_{\text {hitung }}$ untuk variabel keefektifan pengendalian internal sebesar 20,820 dengan nilai signifikan 0,000 , sedangkan $t_{\text {tabel }}$ adalah 1,68 sehingga $t_{\text {hitung }}>t_{\text {tabel }}$ $(20,820>1,68)$. Kemudian dari uji ANOVA atau $F$ test, diperoleh $F_{\text {hitung }}$ sebesar 433.488 dengan tingkat signifikansi 0,000 , dan $F_{\text {tabel }}$ sebesar 3,09 dengan signifikansi 0,05 yang artinya keefektifan pengendalian internal berpengaruh signifikan terhadap kecenderungan kecurangan akuntansi.

\section{SARAN}

Berdasarkan kesimpulan diatas maka saran-saran yang dapat diberikan pada penelitian selanjutnya adalah : hendaknya pimpinan lebih meningkatkan pengendalian internal agar dapat meminimalisir adanya kecenderungan kecurangan akuntansi baik itu pada instansi pemerintah maupun pada perusahaan-perusahaan swasta., pimpinan juga harus dapat membantu karyawan yang tertarik untuk memahami dan mengetahui betapa pentingnya pencegahan kecurangan akuntansi pada instansi yang dipimpinnya sehingga tercapainya tujuan organisasi.

\section{DAFTAR PUSTAKA}

[1] Krismiaji, 2010. Sistem Informasi Akuntansi. Penerbit UPP STIM YKPN. Yogyakarta.

[2] Oktaviani, W., Gunawan, H., Utomo, H., 2015. Pengaruh Pengendalian Internal dalam Pencegahan Fraud (Kecurangan) Terhadap Kinerja Perusahaan (Studi KasusPada BUMN dalam Bidang Industri dan Jasa 
Asuransi di Kota Bandung dan Bandung Barat, Jawa Barat. Prosiding Penelitian SPeSIA..

[3] Herniyetti, 2010. Pengaruh Penerapan Pengendalian Internal Terhadap Pencegahan Fraud Pegadaan Barang. Jurnal Volume 14 No. 2.

[4] Yustisi,Andriany. 2013. Pengaruh Kualifikasi Auditor Internal Terhadap Pencegahan Fraud (Kecurangan)Pengadaan Barang. Bandung. Universitas Pasundan.

[5] Amelia, Lubis Rumondang, 2016. Pengaruh Efektifitas Pengendalian Intern, Gaya Kepemimpinan, Dan Pengembangan Mutu Karyawan Terhadap Pencegahan Kecurangan Akuntansi Pada RSU. Dr. Pirngadi Medan. Skripsi Fakultas Ekonomi,Universitas Sumatera Utara, Medan.

[6] Sugiyono.2013.Metode Penelitian Kuantitatif, Kualitatif Dan R\&D. Bandung. Alfabeta.

[7] Soejono dan Abdurrahman, 2011. Metode Penelitian Suatu Pemikiran dan Penerapan. Rineka Cipta. Jakarta.

[8] Walidin, W., Saifullah, Tabrani, 2015. Metode Peenelitian Kualitatif dan Grounded Theory. FTK Ar-Rainy Press. Banda Aceh.

[9] Sutrisno, Hadi. 2013.Metodologi Penelitian. Yogyakarta: Fakultas Psikologi Universitas Gajah Mada.

[10] Sekaran, Uma. 2011. Metode Penelitian Ilmiah. Jakarta: Salemba Empat. 